Article

\title{
Investigation of the LCST-Thermoresponsive Behavior of Novel Oligo(Ethylene Glycol)-Modified Pentafluorostyrene Homopolymers
}

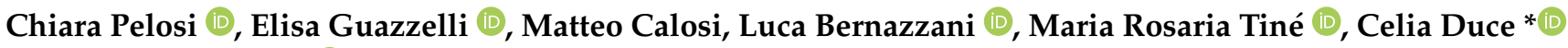 \\ and Elisa Martinelli *(D)
}

check for

updates

Citation: Pelosi, C.; Guazzelli, E.; Calosi, M.; Bernazzani, L.; Tiné, M.R.; Duce, C.; Martinelli, E. Investigation of the LCST-Thermoresponsive Behavior of Novel Oligo(Ethylene Glycol)-Modified Pentafluorostyrene Homopolymers. Appl. Sci. 2021, 11, 2711. https://doi.org/10.3390/ app11062711

Academic Editor: Paola Lova

Received: 2 March 2021

Accepted: 15 March 2021

Published: 18 March 2021

Publisher's Note: MDPI stays neutral with regard to jurisdictional claims in published maps and institutional affiliations.

Copyright: (c) 2021 by the authors. Licensee MDPI, Basel, Switzerland. This article is an open access article distributed under the terms and conditions of the Creative Commons Attribution (CC BY) license (https:// creativecommons.org/licenses/by/ $4.0 /)$.
Dipartimento di Chimica e Chimica Industriale, Università di Pisa, 56124 Pisa, Italy; chiara.pelosi92@gmail.com (C.P.); elisa.guazzelli@dcci.unipi.it (E.G.); matteocalosi@gmail.com (M.C.); luca.bernazzani@unipi.it (L.B.); mariarosaria.tine@unipi.it (M.R.T.)

* Correspondence: celia.duce@unipi.it (C.D.); elisa.martinelli@unipi.it (E.M.)

Featured Application: The combined use of light scattering, turbidimetry, and differential scanning calorimetry highlighted the thermoresponsive self-assembling behavior in water of the oligo(ethylene glycol)-modified pentafluorostyrene homopolymers. The potential applications of such novel smart materials are open to study in advanced fields, including nano-medicine, nano-catalysis and bottom-up nanotechnology at large.

Abstract: Amphiphilic tetrafluorostyrene monomers (EFS8) carrying in the para position an oligoethylene glycol chain containing 8 oxyethylenic units on average were synthesized and used for preparation via activator regenerated by electron transfer atom transfer radical polymerization (ARGET-ATRP) of the corresponding amphiphilic homopolymers ( $p E F S 8-x$ ) with different degrees of polymerization $(x=26$ and 46$)$. Combining light transmittance and nano-differential scanning calorimetry (n-DSC) measurements revealed that pEFS8-x homopolymers displayed a lower critical solution temperature (LCST) thermoresponsive behavior in water solutions. Moreover, n-DSC measurements revealed the presence in heating scans of a broad endothermic peak ascribable to the dehydration process of the polymer single chains (unimers) and their collapse into aggregates. Consistently, dynamic light scattering (DLS) measurements showed below the LCST the presence of small nanostructures with a hydrodynamic diameter size $D_{\mathrm{h}}$ of 6-7 nm, which collapsed into concentration-dependent larger multichain aggregates $\left(D_{\mathrm{h}}=300-3000 \mathrm{~nm}\right)$ above LCST. Interestingly, n-DSC data showed that the unimer-aggregate transition was reversible up to a specific temperature ( $T_{\text {rev }}$ ) of each homopolymer, which in any case was higher than $T_{\max }$. When heating above $T_{\text {rev }}$ the transition was no longer reversible, causing the shift of $T_{\text {onset }}$ and $T_{\max }$ at lower values, thus suggesting an increase in hydrophobicity of the polymer systems associated with a temperature-dependent dehydration process.

Keywords: amphiphilic polymer; thermoresponsive polymer; LCST; DSC; DLS; turbidimetry

\section{Introduction}

Stimuli-responsive polymers show their potential in the variations of properties upon the application of an external stimuli [1]. Their peculiarities have attracted increasing interest in recent decades for their potential applications as smart materials, e.g., in drug delivery [2], tissue engineering [3], biosensing [4], and smart coating [5]. Among various possible stimuli, temperature is the most commonly exploited due to the ease of applying the stimulus, the possible applications in biological systems, and the often reversible nature of the change in properties of the polymer [6]. Thermoresponsive polymers can phase separately from a solution when temperature is increased or decreased, resulting in a miscibility gap in the phase diagram. If raising the temperature causes the immiscibility, 
the mixture exhibits lower critical solution temperature (LCST) behavior, whereas if the opposite is true, it exhibits upper critical solution temperature (UCST). The critical solution temperatures are considered the point of the minimum or maximum of the coexistence curve on the phase diagram, whereas the temperature at which a solution of a given concentration undergoes phase separation is called the cloud point temperature $\left(T_{\mathrm{cp}}\right)$.

Systems possessing LCST are the most extensively studied of the two classes [7]. Thermodynamically, the separation between the two phases is caused by a negative entropy of mixing between the polymer and the solvent, an element increasing in importance with temperature. This counteracts the favorable exothermic enthalpy contribution that is due to the formation of hydrogen bonds between the hydrophilic components of the polymer and the surrounding water molecules $[8,9]$. When the temperature at which the entropic term prevails is reached, the hydrated conformation, present at low temperatures, changes to a contracted conformation, minimizing contact with water, and the contracted polymer coils start aggregating into larger structures. LCST-thermoresponsive polymers are commonly described as subject to a coil-to-globule transition. This describes the conformational changes that a dissolved polymeric chain in an unfolded random coil conformation undergoes when reaching cloud point temperature, a contraction of the structure into a compact globule, which is accompanied by an aggregation of polymers due to hydrophobic interactions becoming dominant upon the loss of bound water [10,11]. However, LCST-like phase separation is also a feature of other kinds of systems where polymer chains are not dissolved into a random coil conformation, but rather are dispersed into small globular structures even below the cloud point. Such globular particles may be constituted by a number of macromolecules self-assembling into micellar structures $[12,13]$ or by a single polymeric chain self-folding into a compact nanoparticle, commonly termed a unimer micelle [14-16], which is generated by intra-macromolecular hydrophobic interactions.

The most common way to measure the cloud point for a thermoresponsive polymer is through turbidimetry measurements [17], thanks to the formation of a heterogeneous milky dispersion above this temperature. Dynamic light scattering (DLS) is also employed to study the size of polymer aggregation below and above the phase transition, as well as to detect such a transition. Differential scanning calorimetry (DSC) is another promising technique useful to study the transition by looking at the heat exchanged during a thermal scan. Despite its potential, the calorimetric evaluation of the phase transition is not so common in the literature. Extensive calorimetric investigations have been reported for the class of poly( $N$-isopropylacrylamide) PNIPAM, one of the most studied systems among thermoresponsive polymers [18-23]. In particular, the studies in the field report a coil-toglobule transition caused by dehydration of the polymer chains during the heating scan followed by their aggregation into concentrated solutions. Both the dehydration and the aggregation processes were found to be kinetically controlled, with the enthalpy and the transition temperature dependent on the scanning rate and the polymer concentration [21]. The reversibility of the process was observed by looking at the dissolution of the aggregates upon cooling. Measurements made at low scan rates on the cooling scan showed the coexistence of two different processes, namely, the disruption of the intra-chain hydrogen bonds created upon the collapse of the chains, and the dissolution of the aggregates [24]. The shape of the cooling peak was therefore dependent upon the aggregation state reached by the polymer, i.e., small dispersed clusters in diluted solutions, large precipitate clusters, or hydrogels in concentrated solutions [21].

In contrast to the studies carried out on classical coil-to-globule thermoresponsive polymers, an extensive calorimetric investigation of the transition is often missing for polymers possessing a globule-to-aggregate transition, and, for example, is absent in the field of thermoresponsive polymers capable of self-folding into unimer micelles. One interesting example showing the potentialities of calorimetry in this field was reported by Kressler et al. [13], who published a paper with the synthesis, morphologic, and calorimetric characterization of the phase transition for telechelic PNIPAM modified with a perfluorinated end-group. The polymer was capable of assembling at room temperature 
into small micelles with a hydrodynamic diameter $\left(D_{\mathrm{h}}\right)$ of $24 \mathrm{~nm}$ and possessed an LCST phase transition, forming larger aggregates above the cloud point temperature. The transition studied ended up being completely reversible and much sharper with respect to the non-reversible larger peak obtained with the azide-terminated precursor, suggesting that cooperative effects in the transition were provided by the presence of the hydrophobic fluorinated groups in the chain. However, no more specific mechanistic hypotheses on the aggregation process were reported in the paper.

Thermoresponsive polymers containing poly (ethylene glycol) (PEG) groups have gained increasing interest in the last two decades due to the high biocompatibility offered by PEG. (Meth)acrylates containing PEG side chains have been frequently used as basic monomers to form thermoresponsive poly(oligo(ethylene glycol) methyl ether methacrylate (POEGMA)-based polymers). At first glance, this class of polymers undergoes a fully reversible transition, in contrast to PNIPAM [25], but there are no in-depth calorimetric studies in the literature that support this assumption. Indeed, when micro-calorimetry was used to study the transition of POEGMA grafted on cellulose nanocrystals, this was shown to involve hysteresis upon cooling [26].

Examples of amphiphilic random copolymers possessing an LCST-type transition are obtained by the copolymerization of oligo(ethylene glycol) methyl ether methacrylate (OEGMA) and fluorinated monomers [15,27-29], including pentafluorostyrene (PFS). The latter system has been shown to possess a well-tunable $T_{\mathrm{cp}}[30]$ and is also capable of self-assembling or self-folding even below this temperature in small micellar structures (down to $10 \mathrm{~nm}$ in diameter) [31,32]. An alternative route to obtaining an amphiphilic homopolymer based on PFS would be to exploit the facile substitution of the fluorine atom in the para position of the pentafluorostyrene monomer [33] to introduce a hydrophilic oligo(ethylene glycol) segment capable in principle of providing thermoresponsive behavior. Amphiphilic PFS-based copolymers, containing triethylene glycol grafts, have been studied for their anti(bio)fouling activities, but are not water-soluble [34-39].

In this paper, we report on the synthesis of amphiphilic PFS-based homopolymers $\mathrm{p}(\mathrm{EFS}) \mathrm{x}$ derived from the atom transfer radical polymerization (ATRP) of a pentafluorostyrene monomer substituted in the para position with an oligo(ethylene glycol)chain $\left(M_{\mathrm{n}}=300 \mathrm{~g} / \mathrm{mol}\right)$. The $\mathrm{p}(\mathrm{EFS}) \times \mathrm{x}$ homopolymers were found to display a thermoresponsive behavior, being able to self-assemble into small nanoparticles below their critical solution temperature and collapse into larger multichain aggregates above the cloud point. Such an aggregation mechanism was investigated by the combined use of light scattering, turbidimetry, and differential scanning calorimetry.

\section{Materials and Methods}

2,3,4,5,6-Pentafluorostyrene (PFS) (Fluorochem, Hadfield, United Kingdom), poly(ethylene glycol) monomethyl ether (mPEG8, average $M_{\mathrm{n}}=350 \mathrm{Da}$ ) (Sigma-Aldrich, Darmstadt, Germany), and tin(II) 2-ethylhexanoate ( $\mathrm{Sn}(\mathrm{EH})_{2}$ ) (Sigma-Aldrich, Darmstadt, Germany) were used as received. Anisole (Sigma-Aldrich, Darmstadt, Germany) was vacuum distilled over sodium, tetrahydrofuran (THF) (Sigma-Aldrich, Darmstadt, Germany) was refluxed over calcium hydride for $3 \mathrm{~h}$ and distilled under nitrogen, $N, N, N^{\prime}, N^{\prime \prime}, N^{\prime \prime}$ pentamethyldiethylenetriamine (PMDTA) and (1-bromoethyl)benzene (1-BEB) (SigmaAldrich, Darmstadt, Germany) were vacuum distilled, and $\mathrm{CuBr}_{2}$ (Sigma-Aldrich, Darmstadt, Germany) was recrystallized from a filtered aqueous solution. Solvents were purchased from Sigma-Aldrich (Darmstadt, Germany) and used as received.

${ }^{1} \mathrm{H}$ and ${ }^{19} \mathrm{~F}$ nuclear magnetic resonance (NMR) measurements were carried out on a Bruker (Billerica, Massachusetts, MA, USA) Avance $400(400 \mathrm{MHz})$ spectrometer with deuterated solvents (Sigma-Aldrich, Darmstadt, Germany) at room temperature. The sample concentration was approximately $30 \mathrm{~g} / \mathrm{L}$. For ${ }^{19} \mathrm{~F}$ NMR chemical shift attribution, hexafluorobenzene was used as the internal standard, to which a chemical shift of $-161.64 \mathrm{ppm}$ is attributed in $\mathrm{CDCl}_{3}$ compared to $\mathrm{CFCl}_{3}$. For ${ }^{1} \mathrm{H}$ spectra the internal standard was the solvent peak. 
The number and weight average molecular weights $\left(M_{\mathrm{n}}, M_{\mathrm{w}}\right)$ were determined by gel permeation chromatography (GPC) using a Jasco (Hachioji-shi, Tokyo, Japan) PU2089Plus liquid chromatograph equipped with two PL gel $5 \mu \mathrm{m}$ mixed-D columns, a Jasco RI-2031 Plus refractive index detector, and a Jasco UV-2077Plus UV/vis detector. Measurements were carried out using chloroform as the mobile phase at a flow rate of $1 \mathrm{~mL} / \mathrm{min}$ and a temperature of $30^{\circ} \mathrm{C}$ maintained by a Jasco CO 2063 Plus column thermostat. Polystyrene standards (Sigma-Aldrich Darmstadt, Germany) were used for calibration. The refractive index detector was used to obtain reported values. Samples were filtered with a $0.2 \mu \mathrm{m}$ polytetrafluoroethylene (PTFE) filter before injection.

UV-Vis measurements were carried out using a Perkin-Elmer (Waltham, MA, USA) Lambda 650 and a Shimadzu (Kyoto, Japan) 2450 spectrometer. Samples were put into quartz cuvettes with a $10 \mathrm{~mm}$ optical path. Transmittance was measured at a fixed wavelength of $700 \mathrm{~nm}$. The cloud point temperature $\left(T_{\mathrm{cp}}\right)$ was defined as the temperature at which transmittance decreased to $50 \%$. Aqueous solutions of the polymers at different concentrations (from 0.1 to $30 \mathrm{~g} / \mathrm{L}$ ) were tested. Measurements were taken at various temperatures, ranging from room temperature to higher than the $T_{\mathrm{cp}}$ of the given substance. The temperature was varied manually using a thermostat.

DLS measurements were carried out in polymer solutions with a Malvern (Malvern, Worcestershire, United Kingdom) Zetasizer Nano ZS particle analyzer (detection angle $=173^{\circ}$ ). Intensity, volume, and number distributions were obtained from the signal autocorrelation function through CONTIN analysis in the instrument software. Samples were prepared using high pressure liquid chromatography (HPLC)-grade water filtered through a $0.2 \mu \mathrm{m}$ cellulose acetate filter. After dissolving the chosen substance, the solution was then filtered through a $5 \mu \mathrm{m}$ cellulose acetate filter. At least 5 separate measurements were carried out for each solution. When all the results were coherent with each other, an average size distribution curve created by the instrument software was considered as an overall representative of the system. Reported hydrodynamic diameters are always calculated according to the intensity size distribution. To investigate the aggregation during the phase separation process, temperature-dependent DLS measurements were performed. Solutions of $5 \mathrm{~g} / \mathrm{L}$ in the water of each polymer were thus prepared and studied below and above the cloud point temperature, at $25^{\circ} \mathrm{C}$ and $80^{\circ} \mathrm{C}$, respectively. Solutions of 0.5 and $10 \mathrm{~g} / \mathrm{L}$ of pFES8-46 were also tested.

Calorimetric measurements were carried out on polymer solutions of $0.5,1$, and $5 \mathrm{mg} / \mathrm{mL}$ in deionized water with a Calorimetry Science Corporation (Lindon, Utah, U.S.) N-DSC III model CS-6300 equipped with capillary cells. For all the experiments, subsequent heating-cooling cycles were performed in an appropriate temperature range, at a $1{ }^{\circ} \mathrm{C} / \mathrm{min}$ scan rate, and the equilibration time between each ramp was set to $60 \mathrm{~s}$. All the samples were degassed and filtered before the measurements, following the standard nanodifferential scanning calorimetry (n-DSC) procedure [40]. The blank scan was performed by filling the sample and the reference cells with $\mathrm{mQ}$ water in the same experimental conditions. Data were analyzed by means of NanoAnalyze software (version 3.11.0). When the samples were heated up to $90^{\circ} \mathrm{C}$, the presence of aggregation phenomena made it difficult to calculate the area of the peak, which was in any case evaluated by assuming the linear extrapolation of the specific heat capacity as the baseline below the peak. The onset temperature ( $\left.T_{\text {onset }}\right)$ was defined as the intercept between the line passing by the first inflection point of the curve and the extrapolated specific heat capacity $\left(C_{p}\right)$ of the sample before the transition. The peak $\left(T_{\max }\right)$ was defined as the temperature at the maximum value of $C_{\mathrm{p}}$. The reversibility of the samples was evaluated by performing several heating/cooling cycles at a $1{ }^{\circ} \mathrm{C} / \mathrm{min}$ scan rate, with $60 \mathrm{~s}$ of equilibration time between each ramp, increasing the final temperature by 2 or $3{ }^{\circ} \mathrm{C}$ every two cycles.

\subsection{Synthesis of the Monomer EFS-8}

A NaH $60 \mathrm{wt} \%$ dispersion in mineral oil $(0.264 \mathrm{~g}, 11.0 \mathrm{mmol})$ was slowly added under $\mathrm{N}_{2}$ to a magnetically stirred solution of mPEG8 (3.501 $\left.\mathrm{g}, 10.0 \mathrm{mmol}\right)$ in anhydrous THF 
$(30 \mathrm{~mL})$ in a $100 \mathrm{~mL}$ three-neck round-bottomed flask in an ice bath. The solution was stirred for $30 \mathrm{~min}$, then PFS $(2.07 \mathrm{~mL}, 15.0 \mathrm{mmol})$ dissolved in $5 \mathrm{~mL}$ of anhydrous THF was added slowly by dropping funnel. The reaction was carried out at $0{ }^{\circ} \mathrm{C}$ under $\mathrm{N}_{2}$ for $3.5 \mathrm{~h}$. The reaction mixture was then concentrated under vacuum, dissolved in deionized water, and washed with petroleum ether. The aqueous phase was then extracted with ethyl acetate. The resulting organic phase was dried over anhydrous $\mathrm{MgSO}_{4}$, passed through a neutral alumina column, and evaporated to dryness under vacuum, obtaining a colorless viscous oil. The final product (yield $44 \%$ ) was characterized by ${ }^{1} \mathrm{H}$ and ${ }^{19} \mathrm{~F}$ NMR analyses

${ }^{1} \mathrm{H}$ NMR (chloroform-d): $\delta(\mathrm{ppm})=6.6(\mathrm{dd}, J=18.0,11.92 \mathrm{~Hz}, 1 \mathrm{H},=\mathrm{CH}), 6.0(\mathrm{~d}$, $J=18.0 \mathrm{~Hz}, 1 \mathrm{H}, \mathrm{H}(\mathrm{H}) \mathrm{C}=\mathrm{CH}-\mathrm{Ar}(\operatorname{trans})), 5.6(\mathrm{~d}, J=11.9 \mathrm{~Hz}, 1 \mathrm{H}, \mathrm{H}(\mathrm{H}) \mathrm{C}=\mathrm{CH}-\mathrm{Ar}(\mathrm{cis})), 4.4(\mathrm{t}$, $\left.J=4.5 \mathrm{~Hz}, 2 \mathrm{H}, \mathrm{Ar}-\mathrm{O}-\mathrm{CH}_{2}\right), 3.9-3.5\left(\mathrm{~m}, 32 \mathrm{H}, \mathrm{O}-\mathrm{CH}_{2}-\mathrm{CH}_{2}-\mathrm{O}\right), 3.4\left(\mathrm{~s}, 3 \mathrm{H}, \mathrm{O}-\mathrm{CH}_{3}\right)$.

${ }^{19} \mathrm{~F}$ NMR (chloroform-d, hexafluorobenzene): $\delta(\mathrm{ppm})=-145.1(\mathrm{dd}, J=20.7,8.4 \mathrm{~Hz}$, $2 \mathrm{~F}$, meta $\mathrm{F}),-158.0$ (dd, $J=20.7,8.4 \mathrm{~Hz}, 2 \mathrm{~F}$, ortho $\mathrm{F})$.

\subsection{Synthesis of the Homopolymer pEFS8- $x$}

The procedure for each homopolymerization was identical except for the monomer/ initiator ratio and the type of atmosphere (nitrogen or vacuum). The polymerization of pEFS8-46 under vacuum was described as typical. The $\mathrm{CuBr}_{2} / \mathrm{PMDTA}$ complex $(0.00066 \mathrm{mmol})$ was first added as a $0.0134 \mathrm{M}$ solution in methanol $\left(3 \mathrm{~g} / \mathrm{L}\right.$ of $\left.\mathrm{CuBr}_{2}\right)$ in a $10 \mathrm{~mL}$ Carius tube, which was then dried under vacuum for $1 \mathrm{~h}$. EFS8 $(0.7013 \mathrm{~g}$, $1.34 \mathrm{mmol}), 1-\mathrm{BEB}(3.0 \mu \mathrm{L}, 0.022 \mathrm{mmol})$, and anisole $(1.5 \mathrm{~mL})$ were then added to the tube and the mixture was degassed with three freeze-pump-thaw cycles. Then $\mathrm{SnEH}_{2}(1.4 \mathrm{mg}$, $0.0022 \mathrm{mmol})$ and PMDTA $(0.7 \mu \mathrm{L}, 0.0022 \mathrm{mmol})$ dissolved in $0.1 \mathrm{~mL}$ of anisole were added and three more freeze-pump-thaw cycles were performed before the polymerization was started at $110{ }^{\circ} \mathrm{C}$ under vacuum and with magnetic stirring. After $17.5 \mathrm{~h}$, the reaction was stopped by exposure to air and quenching to room temperature. The crude product was precipitated three times from chloroform into $n$-hexane, then dissolved in chloroform, passed through a neutral alumina column, and evaporated to dryness under vacuum. The final polymer (yield 79\%) containing 46 repeating units of EFS on average was named pEFS8-46 and was characterized by ${ }^{1} \mathrm{H}$ and ${ }^{19} \mathrm{~F}$ NMR and GPC analyses.

${ }^{1} \mathrm{H}$ NMR (acetone-d6): $\delta(\mathrm{ppm})=6.9-7.2(5 \mathrm{H}$, aromatic), 5.0-5.3 (1 H, ArCHBr), 4.2-4.4 (92 H, ArOCH 2 ), 3.4-3.9 (1472 H OCH2), 3.39 (138 H, OCH3), 1.8-3.1 (138 H CHCH $\mathrm{H}_{2}$ ).

${ }^{19} \mathrm{~F}$ NMR (chloroform-d, hexafluorobenzene): $\delta(\mathrm{ppm})=-142.2 /-146.1(2 \mathrm{~F}$, meta $\mathrm{F})$, $-155.9 /-158.0$ (2F, ortho F).

GPC in chloroform: $M_{\mathrm{n}}=19,800 \mathrm{~g} / \mathrm{mol}, \emptyset=1.25$.

\section{Results and Discussion}

\subsection{Polymer Synthesis and Characterization}

We synthesized novel amphiphilic homopolymers based on poly(pentafluorostyrene) modified with an oligo(ethylene glycol) pendant chain in the para position, with the side chain length being around eight repeating units on average. The monomer EFS8 was obtained by adapting an existing procedure used by other authors with triethylene glycol chains [34-36], and was conducted for the synthesis of the present monomer at a lower reaction temperature to avoid the formation of unwanted by-products. Two homopolymers with different number degrees of polymerization $(x=26$ and 46$)$ were prepared by a controlled radical polymerization technique, namely, activator regenerated by electron transfer (ARGET)-atom transfer radical polymerization (ATRP), by using 1-BEB as the initiator, $\mathrm{CuBr}_{2}$ as the catalyst, PMDTA as the ligand, $\mathrm{Sn}(\mathrm{EH})_{2}$ as the reducing agent, and anisole as the solvent at $110{ }^{\circ} \mathrm{C}$, operating either under a nitrogen atmosphere or under vacuum (Scheme 1). Good control of the polymer dispersity $(\bigoplus)$ was achieved as observed by GPC measurements $(Đ<1.3)$. The full results are available in Table 1. 
<smiles>C=Cc1c(F)c(F)c(F)c(F)c1F</smiles>

PFS<smiles>C=Cc1c(F)c(F)c(OCCOC)c(F)c1F</smiles>

EFS8

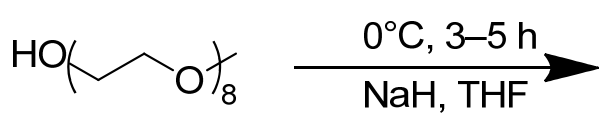

mPEG8<smiles>C=Cc1c(F)c(F)c(OCCOC)c(F)c1F</smiles>

EFS8<smiles>COCCOc1c(F)c(F)c(C(C)(C)CC(C)(C)C)c(F)c1F</smiles>

pEFS8-x

$x=26$ and 46

1-BEB

Scheme 1. Reactions for the synthesis of the monomer EFS8 and the homopolymers pEFS8-x.

Table 1. Physico-chemical properties of the synthesized pEFS8-x polymers.

\begin{tabular}{ccccccc}
\hline Polymer & Atmosphere & $\begin{array}{c}\text { Monomer/ } \\
\text { Initiator Mole Ratio }\end{array}$ & Conversion (\%) & $\mathbf{x}^{\mathbf{1}}$ & $\begin{array}{c}\boldsymbol{M}_{\mathbf{n}} \mathbf{N M R}^{\mathbf{2}} \\
(\mathbf{g} / \mathbf{m o l})\end{array}$ & $\begin{array}{c}\boldsymbol{M}_{\mathbf{n}} \mathbf{G P C}^{\mathbf{3}} \\
(\mathbf{g} / \mathbf{m o l})\end{array}$ \\
\hline pEFS8-26 & $\mathrm{N}_{2}$ & 24 & 99 & 26 & 14,410 & 10,800 \\
pEFS8-46 & Vacuum & 60 & 93 & 46 & 25,490 & 1.26 \\
\hline
\end{tabular}

${ }^{1}$ Number average degree of polymerization. ${ }^{2}$ Molecular weight calculated from $1 \mathrm{H}$ nuclear magnetic resonance (1H NMR). ${ }^{3}$ Molecular weight and dispersity measured by gel permeation chromatography (GPC).

Both EFS8 and the resulting homopolymers were found to be water soluble at room temperature at concentrations up to $30 \mathrm{~g} / \mathrm{L}$, with the resulting solutions being capable of thermoresponsive behavior with an LCST phase separation.

\subsection{Size Characterization in Aqueous Solutions}

The self-assembly properties of pEFS8-26 and pEFS8-46 homopolymers in aqueous solutions were investigated by means of dynamic light scattering (DLS) at room temperature. The homopolymer exhibited a bimodal intensity size distribution at room temperature in aqueous solution $(5 \mathrm{~g} / \mathrm{L})$, with one narrow peak characterized by a hydrodynamic diameter of 6-7 nm and a second, wider one indicating larger diameters (centered at $300 \mathrm{~nm}$ ) (Figure 1). The smaller diameter peak accounted for $99.9 \%$ of particle volume, thus resulting in a unimodal volume distribution. The population at higher diameters may be attributed to the self-assembly of a small portion of polymeric chains into larger multichain aggregates. This kind of bimodal intensity distribution and unimodal volume distribution is a common feature of the self-folding and assembly of amphiphilic random polymers containing fluorous elements $[27,28]$. The dominant population in volume distribution was slightly smaller in size than that previously found for random copolymers of pentafluostyrene and oligo(ethylene glycol) methacrylate (10-15 nm) [32] and it was similar or smaller in size than those measured for self-folded chains formed by other POEGMA-based amphiphilic random copolymers [27,41,42]. Thus, the size of pEFS8-x polymers was compatible with a unimer that, thanks to the amphiphilic nature of the 
polymer, is likely to be in a folded state rather than in a random coiled conformation. An in-depth investigation of the shape and size of the structures formed by pEFS8-x polymers in aqueous solutions is the subject of a forthcoming publication.

(a)

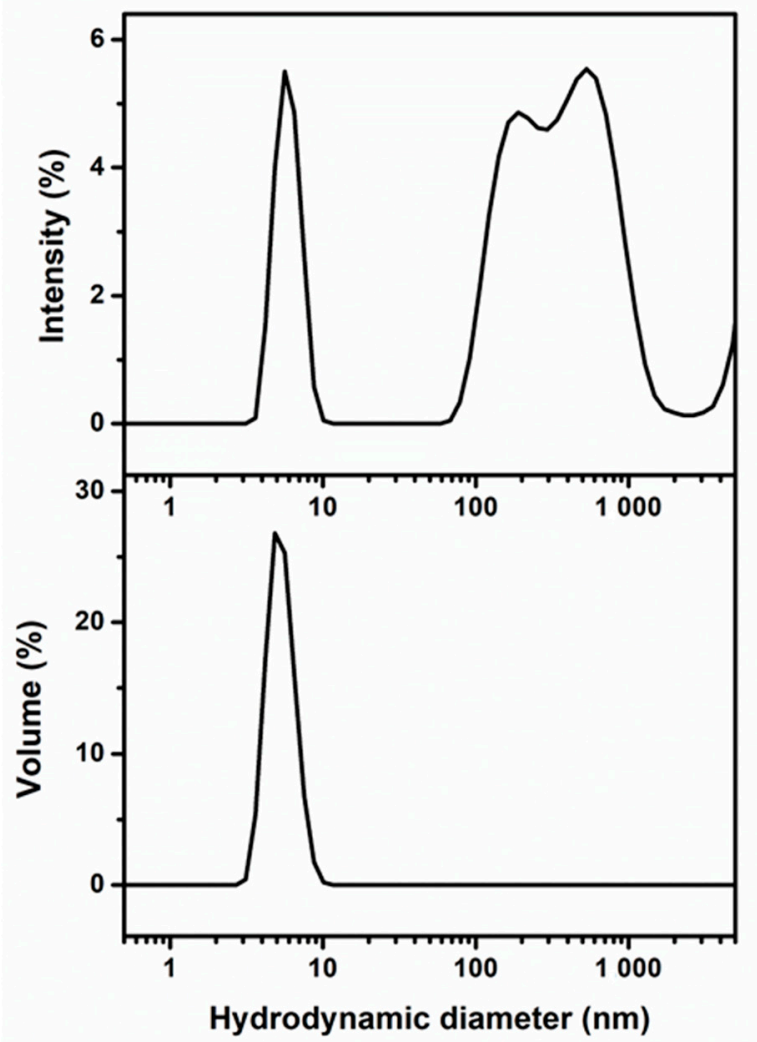

(b)

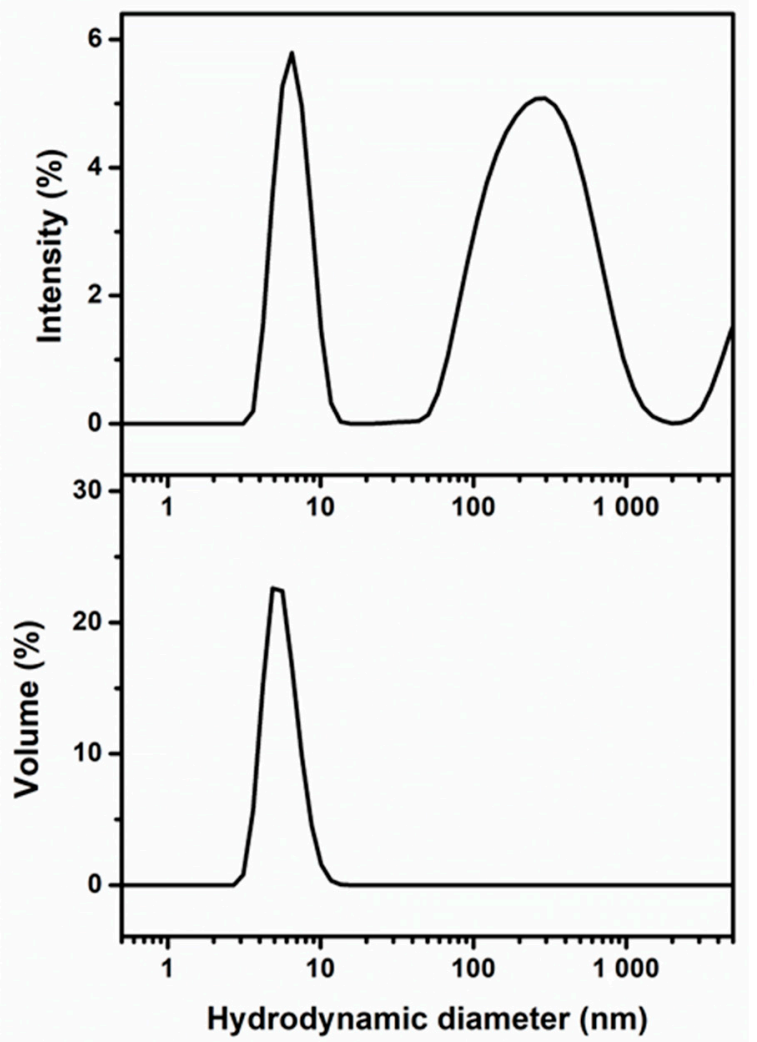

Figure 1. Intensity (above) and volume (below) size distributions of (a) pEFS8-26 and (b) pEFS8-46 at $25^{\circ} \mathrm{C}$.

Both polymers were also studied by DLS at $80^{\circ} \mathrm{C}$. At this temperature, the analysis showed the formation of large multichain aggregates with $D_{\mathrm{h}}$ above 1 micron. In particular, pEFS8-26 formed structures with a $D_{\mathrm{h}}$ of $\sim 3000 \mathrm{~nm}$, whereas pEFS8-46 formed smaller aggregates whose $D_{\mathrm{h}}$ was $\sim 1500 \mathrm{~nm}$, with a size distribution significantly narrower than pEFS8-26. Thus, the average degree of polymerization $x$ seemed to have a far larger effect on the self-assembly of the homopolymers at this higher temperature compared to room temperature. The formation of large aggregates is characteristic of an LCST phase transition, which took place between the two temperatures at which the measurements were carried out.

pEFS8-46 was also studied in aqueous solutions at other concentrations ranging from 0.5 to $10 \mathrm{~g} / \mathrm{L}$ to investigate the influence of polymer concentration on its self-assembly (Table 2). The size distributions at $25{ }^{\circ} \mathrm{C}$ did not change significantly with the concentration, with the dominant population in volume distribution remaining at $7 \mathrm{~nm}$ (Table 2). This indicates that concentration has little influence on the self-assembly of the polymer chains at this temperature. On the other hand, the size distribution at $80{ }^{\circ} \mathrm{C}$ showed a progressive increase in the size of the aggregates with polymer concentration, growing from $340 \mathrm{~nm}$ at $0.5 \mathrm{~g} / \mathrm{L}$ to $2000 \mathrm{~nm}$ at $10 \mathrm{~g} / \mathrm{L}$, where a partial coalescing into even larger particles with a diameter of $5000 \mathrm{~nm}$ was also observed (Figure 2 and Table 2). Overall, pEFS8-x polymer self-assembly above the LCST transition was found to be strongly dependent both on its chain length and concentration in water. 
Table 2. Values of hydrodynamic diameters $D_{h}$ (mean value \pm standard deviation) for pEFS8-x polymers.

\begin{tabular}{ccc}
\hline & $D_{\mathbf{h}}$ at $25^{\circ} \mathbf{C}(\mathbf{n m})$ & $D_{\mathbf{h}}$ at $80^{\circ} \mathbf{C}(\mathbf{n m})$ \\
\hline $\begin{array}{c}\mathrm{pEFS} 8-26 \\
(5 \mathrm{~g} / \mathrm{L})\end{array}$ & $6 \pm 1$ & $3000 \pm 1000$ \\
$\mathrm{pEFS8}-46$ & $7 \pm 2$ & $1500 \pm 300$ \\
$\begin{array}{c}(5 \mathrm{~g} / \mathrm{L}) \\
\mathrm{pEFS8}-46\end{array}$ & $7 \pm 2$ & $340 \pm 60$ \\
$(0.5 \mathrm{~g} / \mathrm{L})$ & $7 \pm 2$ & $2000 \pm 600$ \\
$\mathrm{pEFS8-46}$ & & \\
$(10 \mathrm{~g} / \mathrm{L})$ & &
\end{tabular}

(a)

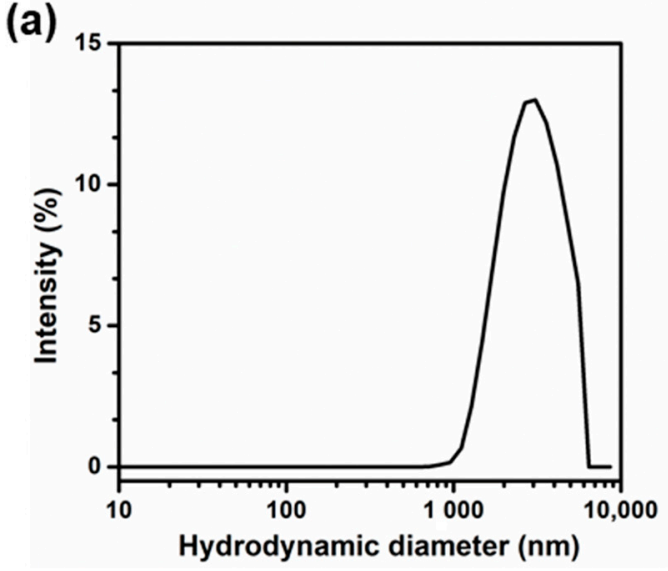

(b)

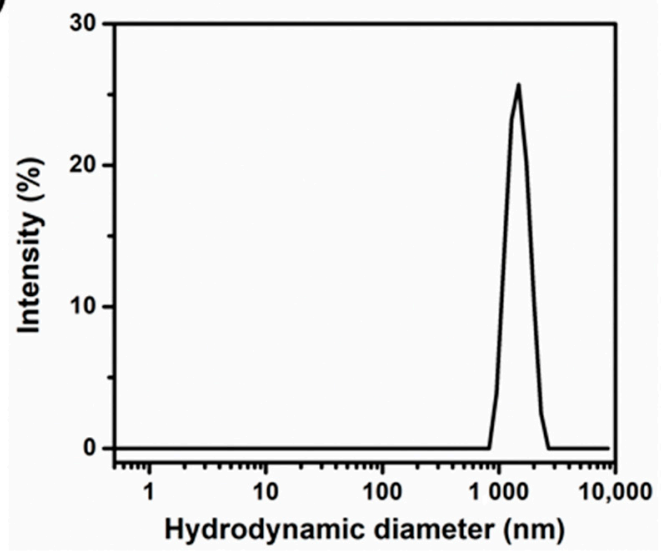

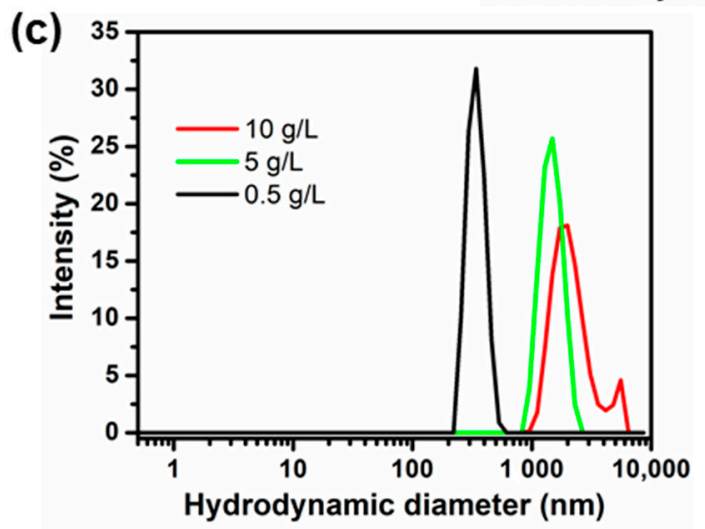

Figure 2. Intensity size distribution at $80{ }^{\circ} \mathrm{C}$ for (a) pEFS8-26 and (b) pEFS8-46 aqueous solution at $5 \mathrm{~g} / \mathrm{L}$ and (c) for pEFS8-46 at various concentrations.

\subsection{Characterization of the Phase Transition}

The thermoresponsiveness of pEFS8-26 and pEFS8-46 in aqueous solutions at different concentrations ranging from 0.5 to $30 \mathrm{~g} / \mathrm{L}$ was tested by turbidimetry using a UV-visible spectrophotometer. The transition due to aggregation phenomena was in general very sharp, being less defined for the lowest investigated concentration of $0.5 \mathrm{~g} / \mathrm{L}$ (Figure 3a,b). The cloud point $\left(T_{\mathrm{cp}}\right)$ temperatures associated with the transition were found to decrease from $83{ }^{\circ} \mathrm{C}$ to $73^{\circ} \mathrm{C}$ up to a plateau value of $71^{\circ} \mathrm{C}$ by increasing the pEFS8-26 polymer concentration from 0.10 to $5 \mathrm{mg} / \mathrm{mL}$ up to $30 \mathrm{mg} / \mathrm{mL}$ (Figure 3c). A similar trend was also valid for pEFS8-46. 
(a)

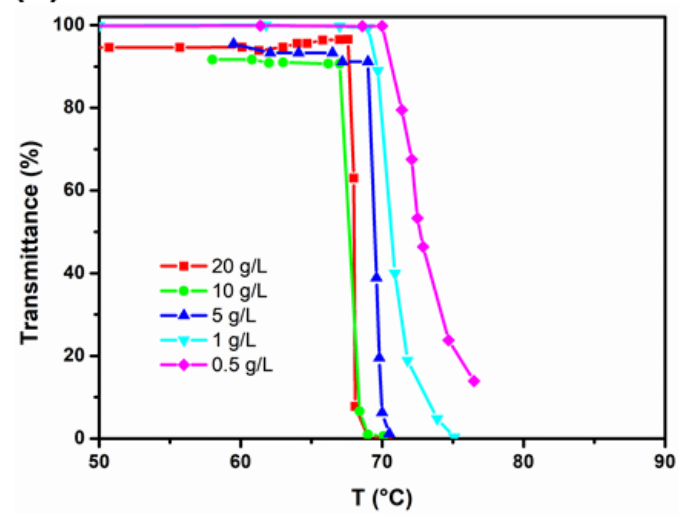

(b)

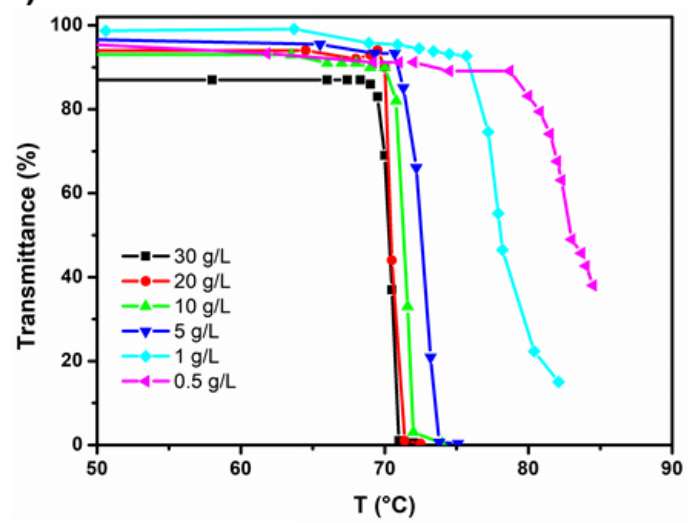

(c)

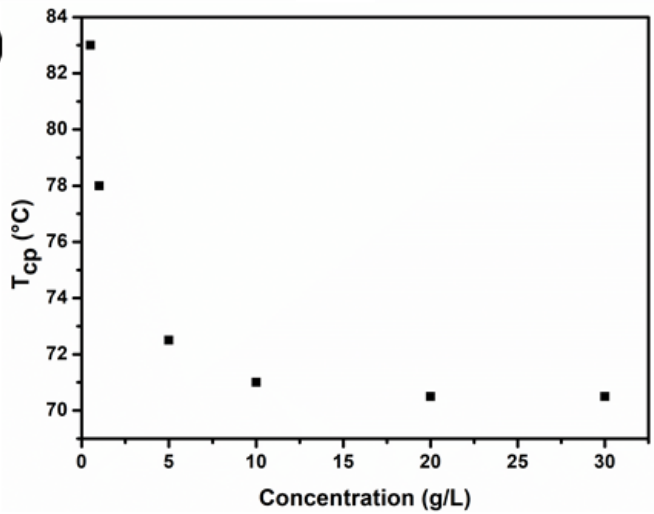

Figure 3. Turbidimetry measurements at different aqueous solution concentrations for (a) pEFS8-26 and (b) pEFS8-46; (c) cloud point temperatures as a function of aqueous solution concentration for pEFS8-26.

Calorimetric measurements were performed on pEFS8-26 and pEFS8-46 aqueous solutions at different concentrations in order to obtain more information on the thermodynamic nature of the LCST. The thermal profiles of pEFS8-26 water solutions at concentrations of $0.5,1$, and $5 \mathrm{mg} / \mathrm{mL}$ are reported in Figure 4. The thermal profiles of pEFS8-46 are presented in Supplementary material Figure S1.

The endothermic peaks observed provided information on the phase transition occurring during the thermal scan. The curves presented a complex profile that suggested the concurrence of different contributions (e.g., the breaking of solvent-polymer hydrogen bonds and the formation of polymer-polymer non-covalent interactions). The overall shape was highly asymmetrical, with a sharp rise of the curve from the onset temperature until the peak maximum and a slow decrease of the curve in the second part, forming a tail. A similar profile is also reported for other thermoresponsive polymers (e.g., PNIPAM [19] and poly(N-vinylcaprolactam) (PVCL)) [43] and the main contribution to the observed endothermic peak was attributed to the breaking of hydrogen bonds among the polymer chains and water, whereas the peak asymmetry was associated with the competition between the dehydration process and the polymer-polymer interchain aggregation in the heating scan [24]. In our case, the latter may have occurred by direct aggregation of self-folded unimers, or by the opening (or partial opening) of the self-folded unimers followed by their aggregation in a more extended conformation, in analogy with the thermal-induced aggregation of protein after the unfolding process [44-47]. A recent small-angle X-ray scattering (SAXS) investigation on the self-assembly behavior in aqueous solution of amphiphilic (meth)acrylic random copolymers containing perfluoroalkyl and oligo(ethylene glycol) side chains highlighted that the aggregation process can be considered an assembling of self-folded unimers in an extended (partially opened) conformation, resulting in a rod-shaped structure [48]. 
(a)

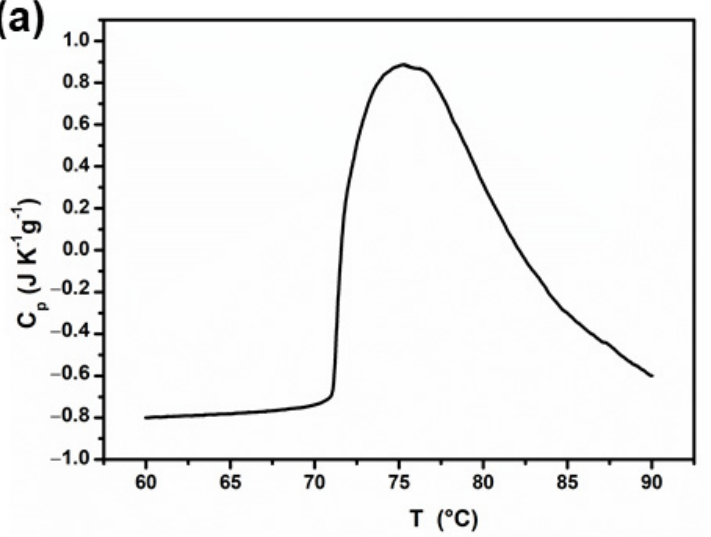

(b)

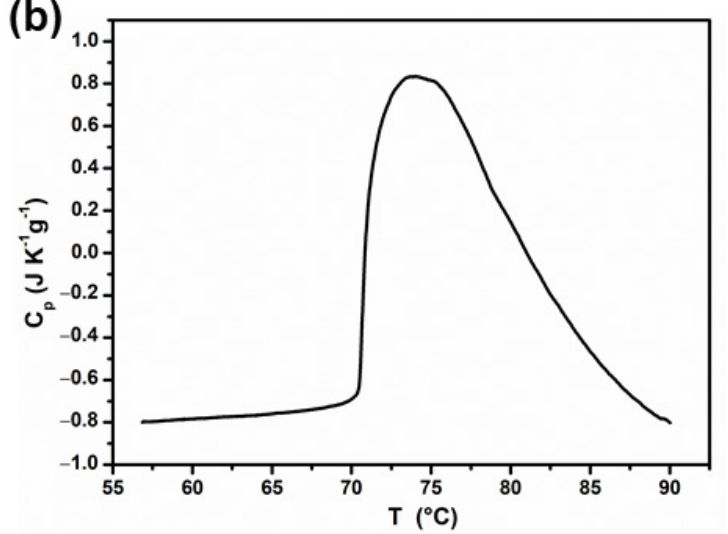

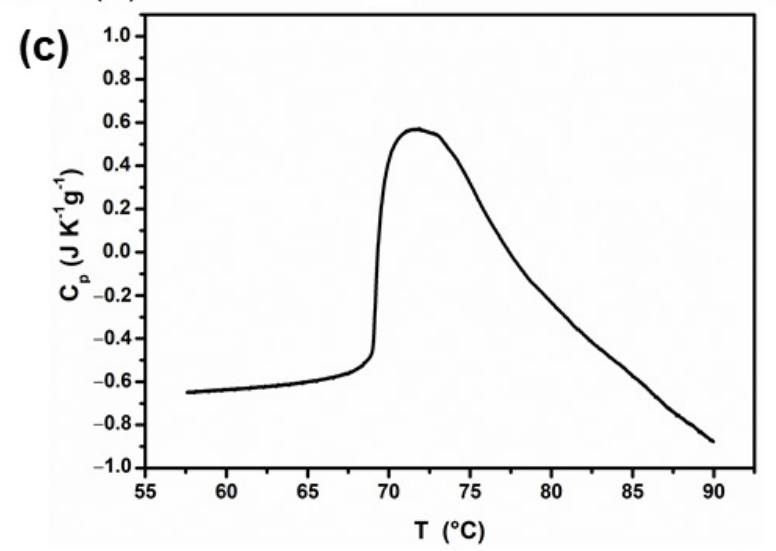

Figure 4. Nano-Differential scanning calorimetry (DSC) thermal profiles of pEFS8-26 aqueous solutions at concentrations of (a) $0.5 \mathrm{~g} / \mathrm{L}$, (b) $1 \mathrm{~g} / \mathrm{L}$, and (c) $5 \mathrm{~g} / \mathrm{L}$.

The onset $\left(T_{\text {onset }}\right)$ and the maximum $\left(T_{\max }\right)$ temperatures in the process are reported in Table 3. Both temperatures decreased with increasing polymer concentrations, consistent with the existence of an LCST-type phase separation. The onset temperatures were associated with the beginning of the dehydration process. $T_{\text {onset }}$ were generally lower than the cloud point temperatures at $50 \%$ transmittance recorded by turbidimetry, especially for pEFS8-46 solutions at lower concentrations, which presented a wider transition (Figure 3b). As for other thermosensitive polymers [49,50], such a difference might be ascribed to the greater sensitivity of the calorimetric technique in detecting the beginning of the phase transition, when the fraction of multichain aggregates is not yet large enough to be detected by turbidimetry.

Table 3. Calorimetric data for $\mathrm{pEFS8-x}$ polymers.

\begin{tabular}{|c|c|c|c|c|c|c|c|}
\hline \multicolumn{6}{|c|}{ First Heating Scan } & \multicolumn{2}{|c|}{ Second Heating Scan } \\
\hline & $\begin{array}{c}\text { Concentration } \\
(\mathrm{g} / \mathrm{L})\end{array}$ & $\begin{array}{c}T_{\text {onset }}{ }^{1} \\
\left({ }^{\circ} \mathrm{C}\right)\end{array}$ & $\begin{array}{c}T_{\max }{ }^{2} \\
\left({ }^{\circ} \mathrm{C}\right)\end{array}$ & $\begin{array}{l}\text { Peak Area } \\
(\mathrm{KJ} / \mathrm{mol})^{3}\end{array}$ & $\begin{array}{l}T_{\mathrm{cp}} 4 \\
\left({ }^{\circ} \mathrm{C}\right)\end{array}$ & $\begin{array}{c}T_{\text {onset }}{ }^{1} \\
\left({ }^{\circ} \mathrm{C}\right)\end{array}$ & $\begin{array}{c}T_{\max }{ }^{2} \\
\left({ }^{\circ} \mathrm{C}\right)\end{array}$ \\
\hline \multirow[t]{3}{*}{ pEFS8-26 } & 0.5 & 71 & 75.2 & 7.6 & 72.5 & 69.5 & 74.4 \\
\hline & 1 & 70.4 & 73.7 & 7.2 & 71 & 68.4 & 72.2 \\
\hline & 5 & 68.7 & 71.7 & 4.5 & 70 & 65.3 & 70.2 \\
\hline \multirow[t]{3}{*}{ pEFS8-46 } & 0.5 & 75.6 & 80.2 & 6.8 & 83 & 75 & 79.8 \\
\hline & 1 & 74.8 & 79.1 & 5.5 & 78 & 73.2 & 78.3 \\
\hline & 5 & 71.8 & 76.8 & / & 73 & 70.7 & 75.2 \\
\hline
\end{tabular}

${ }^{1}$ Onset temperature, reported with an error of $\pm 0.5^{\circ} \mathrm{C} .{ }^{2}$ Peak maximum temperature, reported with an error of $\pm 0.5^{\circ} \mathrm{C} .{ }^{3}$ Per mole of monomeric unit, reported with an error of $\pm 0.7 \mathrm{KJ} / \mathrm{mol} .{ }^{4}$ Cloud point temperature, reported with an error of $\pm 0.5^{\circ} \mathrm{C}$. 
Both $T_{\text {onset }}$ and $T_{\max }$ characteristics of the phase transition increased by increasing the length of the polymer (namely, going from pEFS8-26 to pEFS8-46), suggesting that the higher number of repeating units conferred a higher degree of hydrophilicity to the entire polymer system. The dependence of aggregation temperature on the polymer molecular weight was reported in the literature for several thermoresponsive polymers, e.g., PNIPAM [51] or polyoxazolines [52], whereas others, such as POEGMA [53], do not possess such a dependence.

At the end of the thermal scans $\left(90^{\circ} \mathrm{C}\right)$, none of the curves reached a baseline, but the heat capacity tended to lower values with respect to the initial one $\left(\Delta C_{p}<0\right)$. The heat capacity change was indicative of the solvent-exposed portions of samples, taking into account their polarity [54]. $\Delta C_{p}$ values lower than 0 were found in literature for the denaturation process of proteins in aqueous solutions and were related to the inter-chain aggregation of proteins in the unfolded form [44-47]. In analogy with proteins, we attributed the reduction in the heat capacity of pEFS8-x homopolymers to the formation of multichain aggregates, driven by the minimization of the hydrophobic surface in contact with water. An approximate value of the heat quantity exchanged during the process was calculated by measuring the area underlying the peak. The data is reported in Table 3. We observed that the area calculated in this way was in the range of 5-8 kJ per mole of monomeric unit. This value was similar to that reported for PNIPAM $(\Delta H=5.5-7.5 \mathrm{~kJ} / \mathrm{mol})[22,24,50]$ and slightly higher than that reported for PVCL $(4.2-4.8 \mathrm{~kJ} / \mathrm{mol})$ [43]. As the enthalpy of an LCST phase transition can be used to estimate the number of hydrogen bonds that are broken per monomeric unit, as well as the amount of water retained by the resulting aggregates [17], it is likely that these phenomena are similar in scale for pEFS8 and PNIPAM. Moreover, it was found that, for both polymers, the peak area decreased by increasing the polymer concentration in water, related to the enhancing of aggregation processes, as previously discussed.

The second heating scans had a similar shape as the first ones, but $T_{\text {onset }}$ and $T_{\max }$ were $2-3{ }^{\circ} \mathrm{C}$ earlier (Table 3 ), denoting the non-reversibility of the process in the experimental conditions. We performed repeated temperature scans at different scan rates to evaluate whether and how the shape of the thermograms was affected by the thermal history of the sample and the scanning rate. During a scan of five consecutive heating-cooling cycles for the polymer pEFS8-26, we observed that $T_{\text {onset }}$ and $T_{\max }$ decreased until reaching convergence after three cycles (Figure 5). This behavior, as well as the downshift of the heat capacity before the transition, concurred in indicating an overall increase in the hydrophobicity of the system [55]. In addition, the shape of the curve became more complex and irregular, and the presence of a shoulder immediately after the onset appeared more evident as the number of repeated cycles increased. A similar behavior was also found for the longer polymer chain, pEFS8-46 (Figure S2).

The lack of full reversibility shown by the calorimetric measurements is similar to that observed in some PNIPAM-based polymers $[13,24]$ and seems in general to be a common feature in thermoresponsive polymers when they are investigated by calorimetric techniques. A deeper investigation was performed by repeated heating/cooling scans, increasing the final scan temperature by $2-3{ }^{\circ} \mathrm{C}$ for every two scans. We observed that the transition of pEFS8-26 was reversible up to $76{ }^{\circ} \mathrm{C}$, which was the maximum reversibility temperature $\left(T_{\text {rev }}\right)$. Small differences visible only at the onset temperature of the last two scans revealed the presence of kinetic phenomena (Figure 6a). The calorimetric findings were confirmed by turbidimetry measurements (Figure 6b), which highlighted the absence of hysteresis in heating-cooling cycles. On the other hand, the thermal profiles obtained for pEFS8-26 by performing the same procedure described above were different from each other at temperature above $T_{\text {rev }}=78{ }^{\circ} \mathrm{C}$ (Figure S3a). Consistently, turbidimetry measurements showed hysteresis in repeating heating-cooling cycles (Figure S3b). 


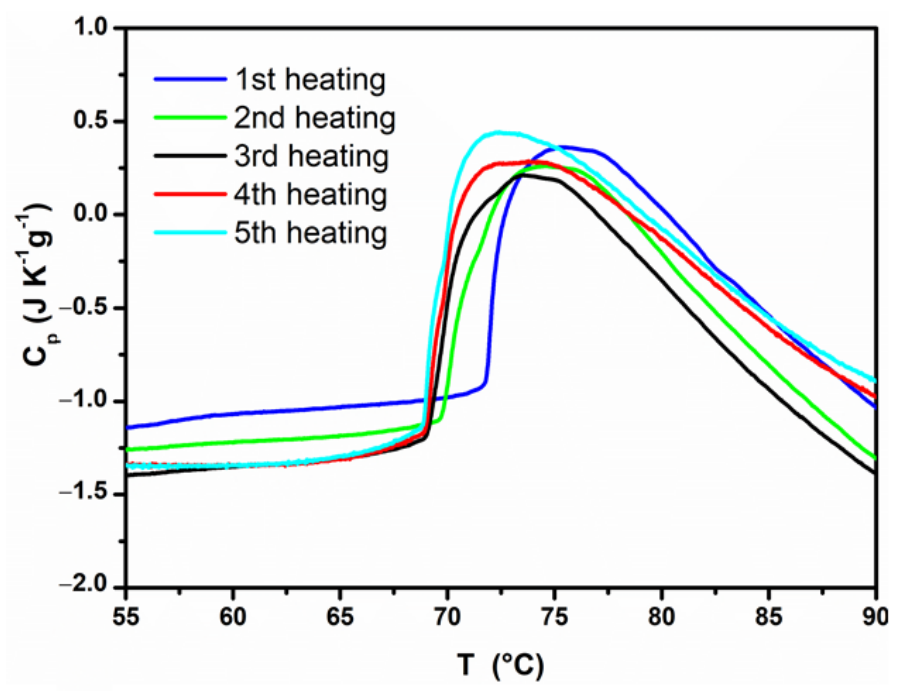

Figure 5. Reversibility of the aggregation process for pEFS8-26 aqueous solutions $(1 \mathrm{~g} / \mathrm{L})$, studied by nano-differential scanning calorimetry (n-DSC). The first three scans were carried out at $1{ }^{\circ} \mathrm{C} / \mathrm{min}$, and the last two at $0.5^{\circ} \mathrm{C} / \mathrm{min}$.

(a)

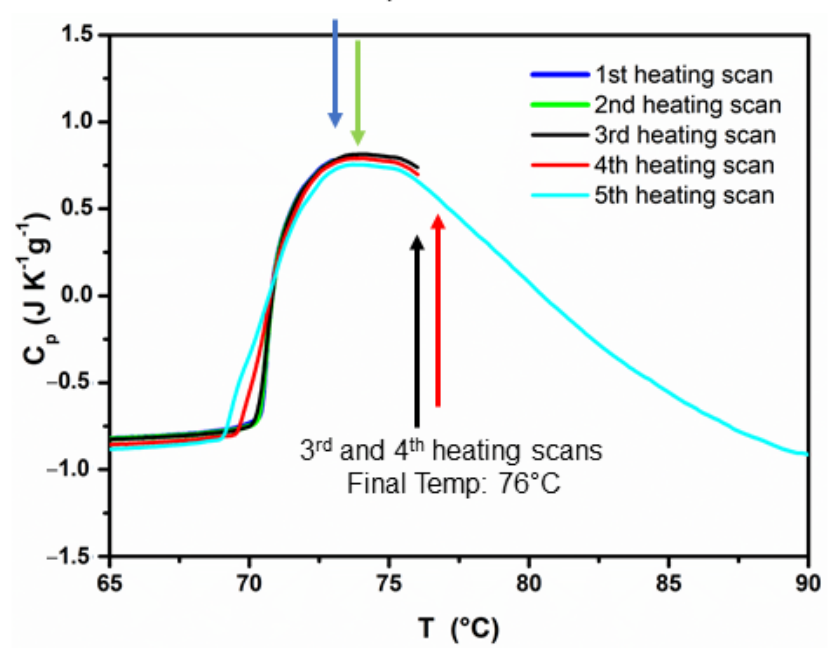

(b)

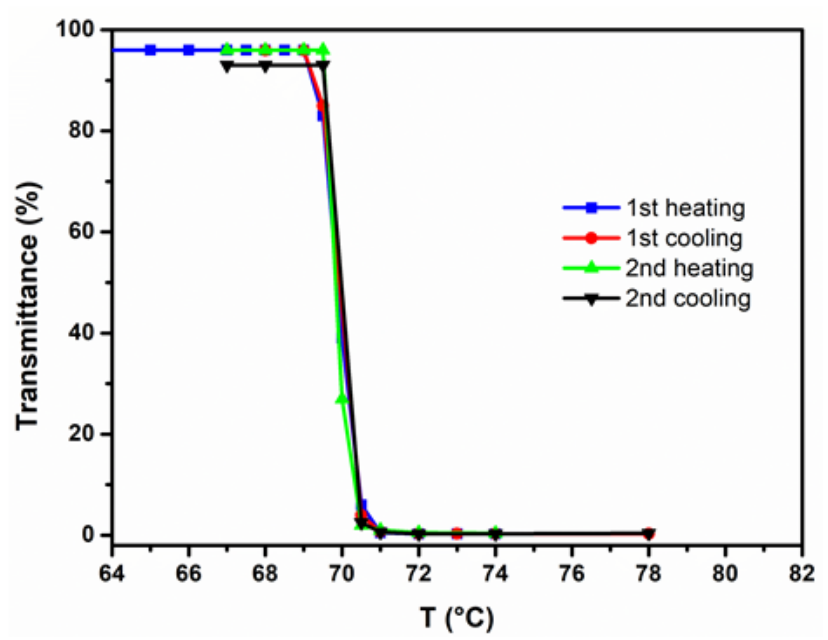

Figure 6. Reversibility of the aggregation process for pEFS8-26 aqueous solution studied by n-DSC (changing the final temperature by $3{ }^{\circ} \mathrm{C}$ every two heating scans) (a) and turbidity measurements (b).

Overall, we can speculate that when the polymer aqueous solution is heated at $T \leq T_{\text {rev }}$ but above $T_{\text {onset, }}$, the unimers in a more globular structure self-assemble into multichain aggregates that reversibly regenerate the original unimer conformation when cooling back below $T_{\text {onset }}$ (Figure 7 top). Differently, when the polymer aqueous solution is heated at $T>T_{\text {rev }}$ a more marked dehydration process occurs that possibly leads to conformational changes in the multichain aggregates in which stronger interactions among the perfluorinated main chains are favored in a sort of "melted" hydrophobic core. Such a conformation might therefore prevent the multichain aggregate from regenerating unimers in their original globular structure while promoting the formation of a more opened and extended shape (Figure 7 bottom). This would result in a major exposure of the perfluorinated main chains in contact with water and an increase in the hydrophobicity of the overall polymer system, which in turn causes a reduction in $T_{\text {onset }}$ and $T_{\max }$, and a downshift of the heat capacity before the transition, as discussed above. 


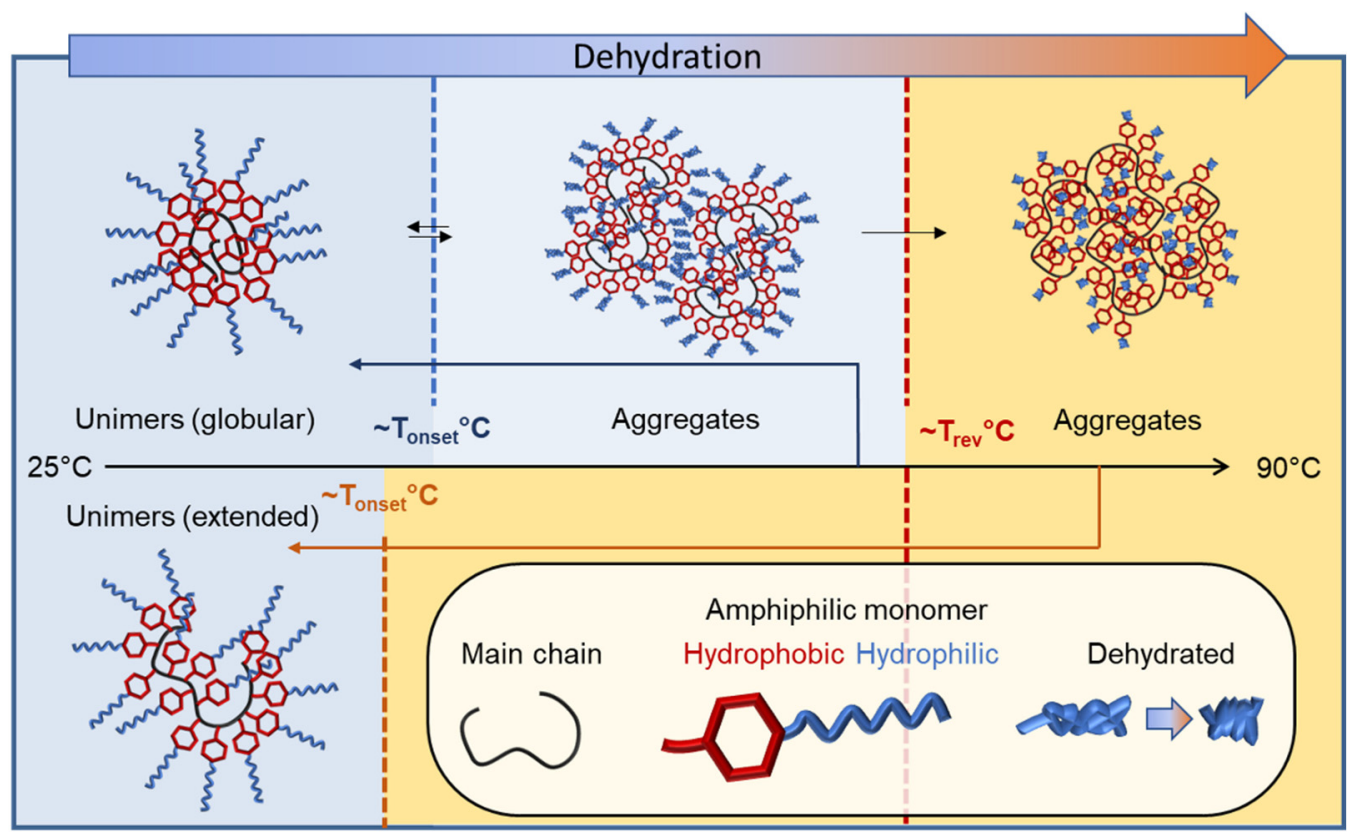

Figure 7. Schematic representation of the self-aggregation process of the amphiphilic homopolymers pEFS8-x below and above $T_{\text {rev. }}$

\section{Conclusions}

Novel amphiphilic homopolymers composed of a poly(pentafluorostyrene) modified in the para position with an oligo(ethyleneglycol) side chain containing eight $\mathrm{CH}_{2} \mathrm{CH}_{2} \mathrm{O}$ units on average were synthesized by ARGET-ATRP. By taking advantage of the controlled nature of the polymerization, two homopolymers with different lengths were prepared and their self-assembling and thermoresponsive behavior in water was investigated by DLS, turbidimetry, and n-DSC. All the analytic techniques pointed out for both polymers the existence of an LCST-type phase transition at which nanostructures with a low $D_{\mathrm{h}}$ of 6-7 nm, consistent with a polymer single chain, self-assembled into much larger multichain aggregates whose dimensions depended on the polymer concentration. The cloud point temperatures $\left(T_{\mathrm{cp}}\right)$ at $50 \%$ transmittance were generally in between the calorimetric $T_{\text {onset }}$ and $T_{\max }$. Moreover, $T_{\mathrm{cp}}, T_{\text {onset, }}$ and $T_{\max }$ were found to be lower for the shorter than for the longer homopolymer. n-DSC measurements revealed, in any case, the presence in heating scans of a broad endothermic peak mainly due to the dehydration process of the polymer single chains and their collapse into aggregates. However, the LCST behavior associated with this unimer-aggregate transition was found to be reversible up to a specific homopolymer-dependent temperature $\left(T_{\text {rev }}\right)$, which was higher than $T_{\max }$ in both cases. On the other hand, when heating above $T_{\text {rev }}$, the transition was no longer reversible, causing the shift of $T_{\text {onset }}$ and $T_{\max }$ at lower values, which was indicative of the increase in hydrophobicity of the polymer systems. This was interpreted by assuming a temperature-dependent dehydration process, resulting in significant changes in unimer and aggregate conformations.

To the best of our knowledge, the obtained results contribute, for the first time, to drawing a general picture to describe the thermoresponsive behavior, and its reversibility, of novel amphiphilic tetrafluorostyrene-based homopolymers in aqueous solutions.

Supplementary Materials: The following are available online at https:/ / www.mdpi.com/2076-341 $7 / 11 / 6 / 2711 / s 1$, Figure S1: DSC thermal profiles of the polymer pEFS8-46 performed in aqueous solution at concentrations of $0.5 \mathrm{~g} / \mathrm{L}$ (a), $1 \mathrm{~g} / \mathrm{L}$ (b), and $5 \mathrm{~g} / \mathrm{L}$ (c). Figure S2. Reversibility of the aggregation process for pEFS8-46 aqueous solutions $(1 \mathrm{~g} / \mathrm{L})$, studied by n-DSC. The first 3 scans were carried out at $1{ }^{\circ} \mathrm{C} / \mathrm{min}$, and the last two at $0.5^{\circ} \mathrm{C} / \mathrm{min}$. Figure $\mathrm{S} 3$. Reversibility of the aggregation 
process for pEFS8-46 aqueous solutions studied by n-DSC (changing the final temperature of the scan every two heating scans) (a) and by turbidity measurements (b).

Author Contributions: Conceptualization, M.R.T., C.D., and E.M.; methodology, C.P., M.C., and E.G.; software, C.P. and M.C.; validation, L.B., C.D., and E.M.; formal analysis, L.B., C.D., and E.M.; investigation, E.M., E.G., M.C., C.P., and C.D.; resources, L.B., M.R.T., C.D., and E.M.; data curation, M.C., C.P., and E.G.; writing-original draft preparation, C.P. and M.C.; writing-review and editing, E.M. and C.D.; visualization, E.M. and C.D.; supervision, L.B., C.D., and E.M.; project administration, E.M. and C.D.; funding acquisition, M.R.T., L.B., and E.M. All authors have read and agreed to the published version of the manuscript.

Funding: This research was funded by the University of Pisa (Progetti di Ricerca di Ateneo, PRA_2020_27 and PRA_2020_32) and by Regione Toscana (Project Ecopool Smart Filter 2017 POR CREO FESR).

Institutional Review Board Statement: Not applicable.

Informed Consent Statement: Not applicable.

Conflicts of Interest: The authors declare no conflict of interest.

\section{References}

1. Wei, M.; Gao, Y.; Li, X.; Serpe, M.J. Stimuli-Responsive Polymers and Their Applications. Polym. Chem. 2016, 8, 127-143. [CrossRef]

2. Priya James, H.; John, R.; Alex, A.; Anoop, K.R. Smart Polymers for the Controlled Delivery of Drugs-A Concise Overview. Acta Pharm. Sin. B 2014, 4, 120-127. [CrossRef] [PubMed]

3. Municoy, S.; Álvarez Echazú, M.I.; Antezana, P.E.; Galdopórpora, J.M.; Olivetti, C.; Mebert, A.M.; Foglia, M.L.; Tuttolomondo, M.V.; Alvarez, G.S.; Hardy, J.G.; et al. Stimuli-Responsive Materials for Tissue Engineering and Drug Delivery. Int. J. Mol. Sci. 2020, 21, 4724. [CrossRef] [PubMed]

4. Hu, L.; Zhang, Q.; Li, X.; Serpe, M.J. Stimuli-Responsive Polymers for Sensing and Actuation. Mater. Horiz. 2019, 6, 1774-1793. [CrossRef]

5. Nagappan, S.; Moorthy, M.S.; Rao, K.M.; Ha, C.-S. Stimuli-Responsive Smart Polymeric Coatings: An Overview. In Industrial Applications for Intelligent Polymers and Coatings; Hosseini, M., Makhlouf, A.S.H., Eds.; Springer International Publishing: Cham, Switzerland, 2016; pp. 27-49. ISBN 978-3-319-26893-4.

6. Kim, Y.-J.; Matsunaga, Y.T. Thermo-Responsive Polymers and Their Application as Smart Biomaterials. J. Mater. Chem. B 2017, 5 , 4307-4321. [CrossRef]

7. Bordat, A.; Boissenot, T.; Nicolas, J.; Tsapis, N. Thermoresponsive Polymer Nanocarriers for Biomedical Applications. Adv. Drug Deliv. Rev. 2019, 138, 167-192. [CrossRef] [PubMed]

8. Schattling, P.; Jochum, F.D.; Theato, P. Multi-Stimuli Responsive Polymers-The All-in-One Talents. Polym. Chem. 2013, 5, 25-36. [CrossRef]

9. de la Rosa, V.R.; Woisel, P.; Hoogenboom, R. Supramolecular Control over Thermoresponsive Polymers. Mater. Today 2016, 19, 44-55. [CrossRef]

10. Umapathi, R.; Reddy, P.M.; Rani, A.; Venkatesu, P. Influence of Additives on Thermoresponsive Polymers in Aqueous Media: A Case Study of Poly(N-Isopropylacrylamide). Phys. Chem. Chem. Phys. 2018, 20, 9717-9744. [CrossRef]

11. Dalgakiran, E.; Tatlipinar, H. The Role of Hydrophobic Hydration in the LCST Behaviour of POEGMA 300 by All-Atom Molecular Dynamics Simulations. Phys. Chem. Chem. Phys. 2018, 20, 15389-15399. [CrossRef]

12. Sambe, L.; Stoffelbach, F.; Lyskawa, J.; Delattre, F.; Fournier, D.; Bouteiller, L.; Charleux, B.; Cooke, G.; Woisel, P. Host-Guest Modulation of the Micellization of a Tetrathiafulvalene-Functionalized Poly(N-Isopropylacrylamide). Macromolecules 2011, 44, 6532-6538. [CrossRef]

13. Li, Z.; Kyeremateng, S.O.; Fuchise, K.; Kakuchi, R.; Sakai, R.; Kakuchi, T.; Kressler, J. Aggregation Behavior of Poly(NIsopropylacrylamide) Semitelechelics with a Perfluoroalkyl Segment in Watera. Macromol. Chem. Phys. 2009, 210, $2138-2147$. [CrossRef]

14. Matsumoto, K.; Terashima, T.; Sugita, T.; Takenaka, M.; Sawamoto, M. Amphiphilic Random Copolymers with Hydrophobic/ Hydrogen-Bonding Urea Pendants: Self-Folding Polymers in Aqueous and Organic Media. Macromolecules 2016, 49, 7917-7927. [CrossRef]

15. Koda, Y.; Terashima, T.; Sawamoto, M. Multimode Self-Folding Polymers via Reversible and Thermoresponsive Self-Assembly of Amphiphilic/Fluorous Random Copolymers. Macromolecules 2016, 49, 4534-4543. [CrossRef]

16. Hattori, G.; Takenaka, M.; Sawamoto, M.; Terashima, T. Nanostructured Materials via the Pendant Self-Assembly of Amphiphilic Crystalline Random Copolymers. J. Am. Chem. Soc. 2018, 140, 8376-8379. [CrossRef] 
17. Zhang, Q.; Weber, C.; Schubert, U.S.; Hoogenboom, R. Thermoresponsive Polymers with Lower Critical Solution Temperature: From Fundamental Aspects and Measuring Techniques to Recommended Turbidimetry Conditions. Mater. Horiz. 2017,4 , $109-116$. [CrossRef]

18. Van Durme, K.; Van Assche, G.; Van Mele, B. Kinetics of Demixing and Remixing in Poly(N-Isopropylacrylamide)/Water Studied by Modulated Temperature DSC. Macromolecules 2004, 37, 9596-9605. [CrossRef]

19. Pham, Q.-T.; Yao, Z.-H.; Chang, Y.-T.; Wang, F.-M.; Chern, C.-S. LCST Phase Transition Kinetics of Aqueous Poly(NIsopropylacrylamide) Solution. J. Taiwan Inst. Chem. Eng. 2018, 93, 63-69. [CrossRef]

20. Liu, P.; Song, L.; Li, N.; Lin, J.; Huang, D. Time Dependence of Phase Separation Enthalpy Recovery Behavior in Aqueous Poly(N-Isopropylacrylamide) Solution. J. Therm. Anal. Calorim. 2017, 130, 843-850. [CrossRef]

21. Yan, Y.; Huang, L.; Zhang, Q.; Zhou, H. Concentration Effect on Aggregation and Dissolution Behavior of Poly(NIsopropylacrylamide) in Water. J. Appl. Polym. Sci. 2015, 132. [CrossRef]

22. Gao, Y.; Yang, J.; Ding, Y.; Ye, X. Effect of Urea on Phase Transition of Poly(N-Isopropylacrylamide) Investigated by Differential Scanning Calorimetry. J. Phys. Chem. B 2014, 118, 9460-9466. [CrossRef]

23. Bischofberger, I.; Calzolari, D.C.E.; De Los Rios, P.; Jelezarov, I.; Trappe, V. Hydrophobic Hydration of Poly-N-Isopropyl Acrylamide: A Matter of the Mean Energetic State of Water. Sci. Rep. 2014, 4, 4377. [CrossRef]

24. Ding, Y.; Ye, X.; Zhang, G. Microcalorimetric Investigation on Aggregation and Dissolution of Poly(N-Isopropylacrylamide) Chains in Water. Macromolecules 2005, 38, 904-908. [CrossRef]

25. Lutz, J.-F.; Akdemir, Ö.; Hoth, A. Point by Point Comparison of Two Thermosensitive Polymers Exhibiting a Similar LCST: Is the Age of Poly(NIPAM) Over? J. Am. Chem. Soc. 2006, 128, 13046-13047. [CrossRef] [PubMed]

26. Grishkewich, N.; Akhlaghi, S.P.; Zhaoling, Y.; Berry, R.; Tam, K.C. Cellulose Nanocrystal-Poly(Oligo(Ethylene Glycol) Methacrylate) Brushes with Tunable LCSTs. Carbohydr. Polym. 2016, 144, 215-222. [CrossRef] [PubMed]

27. Koda, Y.; Terashima, T.; Sawamoto, M.; Maynard, H.D. Amphiphilic/Fluorous Random Copolymers as a New Class of NonCytotoxic Polymeric Materials for Protein Conjugation. Polym. Chem. 2014, 6, 240-247. [CrossRef]

28. Martinelli, E.; Guazzelli, E.; Galli, G.; Telling, M.T.F.; Poggetto, G.D.; Immirzi, B.; Domenici, F.; Paradossi, G. Prolate and Temperature-Responsive Self-Assemblies of Amphiphilic Random Copolymers with Perfluoroalkyl and Polyoxyethylene Side Chains in Solution. Macromol. Chem. Phys. 2018, 219, 1800210. [CrossRef]

29. Guazzelli, E.; Masotti, E.; Biver, T.; Pucci, A.; Martinelli, E.; Galli, G. The Self-Assembly over Nano- to Submicro-Length Scales in Water of a Fluorescent Julolidine-Labeled Amphiphilic Random Terpolymer. J. Polym. Sci. Part Polym. Chem. 2018, 56, 797-804. [CrossRef]

30. Becer, C.R.; Kokado, K.; Weber, C.; Can, A.; Chujo, Y.; Schubert, U.S. Metal-Free Synthesis of Responsive Polymers: Cloud Point Tuning by Controlled “Click" Reaction. J. Polym. Sci. Part Polym. Chem. 2010, 48, 1278-1286. [CrossRef]

31. Zuppardi, F.; Chiacchio, F.R.; Sammarco, R.; Malinconico, M.; Gomez d'Ayala, G.; Cerruti, P. Fluorinated Oligo(Ethylene Glycol) Methacrylate-Based Copolymers: Tuning of Self Assembly Properties and Relationship with Rheological Behavior. Polymer 2017, 112, 169-179. [CrossRef]

32. Zuppardi, F.; Malinconico, M.; D'Agosto, F.; D'Ayala, G.G.; Cerruti, P. Well-Defined Thermo-Responsive Copolymers Based on Oligo(Ethylene Glycol) Methacrylate and Pentafluorostyrene for the Removal of Organic Dyes from Water. Nanomaterials 2020, 10, 1779. [CrossRef]

33. Hvilsted, S. The Pentafluorostyrene Endeavours with Atom Transfer Radical Polymerization—Quo Vadis? Polym. Int. 2014, 63, 814-823. [CrossRef]

34. Bartels, J.W.; Cheng, C.; Powell, K.T.; Xu, J.; Wooley, K.L. Hyperbranched Fluoropolymers and Their Hybridization into Complex Amphiphilic Crosslinked Copolymer Networks. Macromol. Chem. Phys. 2007, 208, 1676-1687. [CrossRef]

35. Powell, K.T.; Cheng, C.; Wooley, K.L. Complex Amphiphilic Hyperbranched Fluoropolymers by Atom Transfer Radical SelfCondensing Vinyl (Co)Polymerization. Macromolecules 2007, 40, 4509-4515. [CrossRef] [PubMed]

36. Martinelli, E.; Pelusio, G.; Yasani, B.R.; Glisenti, A.; Galli, G. Surface Chemistry of Amphiphilic Polysiloxane/TriethyleneglycolModified Poly(Pentafluorostyrene) Block Copolymer Films Before and After Water Immersion. Macromol. Chem. Phys. 2015, 216, 2086-2094. [CrossRef]

37. Imbesi, P.M.; Gohad, N.V.; Eller, M.J.; Orihuela, B.; Rittschof, D.; Schweikert, E.A.; Mount, A.S.; Wooley, K.L. NoradrenalineFunctionalized Hyperbranched Fluoropolymer-Poly(Ethylene Glycol) Cross-Linked Networks as Dual-Mode, Anti-Biofouling Coatings. ACS Nano 2012, 6, 1503-1512. [CrossRef]

38. Oliva, M.; Martinelli, E.; Galli, G.; Pretti, C. PDMS-Based Films Containing Surface-Active Amphiphilic Block Copolymers to Combat Fouling from Barnacles B. Amphitrite and B. Improvisus. Polymer 2017, 108, 476-482. [CrossRef]

39. Martinelli, E.; Hill, S.D.; Finlay, J.A.; Callow, M.E.; Callow, J.A.; Glisenti, A.; Galli, G. Amphiphilic Modified-Styrene Copolymer Films: Antifouling/Fouling Release Properties against the Green Alga Ulva Linza. Prog. Org. Coat. 2016, 90, 235-242. [CrossRef]

40. Michnik, A.; Drzazga, Z.; Kluczewska, A.; Michalik, K. Differential Scanning Microcalorimetry Study of the Thermal Denaturation of Haemoglobin. Biophys. Chem. 2005, 118, 93-101. [CrossRef]

41. Terashima, T.; Sugita, T.; Fukae, K.; Sawamoto, M. Synthesis and Single-Chain Folding of Amphiphilic Random Copolymers in Water. Macromolecules 2014, 47, 589-600. [CrossRef] 
42. Martinelli, E.; Annunziata, L.; Guazzelli, E.; Pucci, A.; Biver, T.; Galli, G. The Temperature-Responsive Nanoassemblies of Amphiphilic Random Copolymers Carrying Poly(Siloxane) and Poly(Oxyethylene) Pendant Chains. Macromol. Chem. Phys. 2018, 219, 1800082. [CrossRef]

43. Laukkanen, A.; Valtola, L.; Winnik, F.M.; Tenhu, H. Formation of Colloidally Stable Phase Separated Poly(N-Vinylcaprolactam) in Water: A Study by Dynamic Light Scattering, Microcalorimetry, and Pressure Perturbation Calorimetry. Macromolecules 2004, 37, 2268-2274. [CrossRef]

44. Sanchez-Ruiz, J.M. Theoretical Analysis of Lumry-Eyring Models in Differential Scanning Calorimetry. Biophys. J. 1992, 61, 921-935. [CrossRef]

45. Benjwal, S.; Verma, S.; Röhm, K.-H.; Gursky, O. Monitoring Protein Aggregation during Thermal Unfolding in Circular Dichroism Experiments. Protein Sci. Publ. Protein Soc. 2006, 15, 635-639. [CrossRef]

46. Borzova, V.A.; Markossian, K.A.; Chebotareva, N.A.; Kleymenov, S.Y.; Poliansky, N.B.; Muranov, K.O.; Stein-Margolina, V.A.; Shubin, V.V.; Markov, D.I.; Kurganov, B.I. Kinetics of Thermal Denaturation and Aggregation of Bovine Serum Albumin. PLoS ONE 2016, 11, e0153495. [CrossRef]

47. Pelosi, C.; Saitta, F.; Wurm, F.R.; Fessas, D.; Tinè, M.R.; Duce, C. Thermodynamic Stability of Myoglobin-Poly(Ethylene Glycol) Bioconjugates: A Calorimetric Study. Thermochim. Acta 2019, 671, 26-31. [CrossRef]

48. Domenici, F.; Guazzelli, E.; Masotti, E.; Mahmoudi, N.; Gabrielli, S.; Telling, M.T.F.; Martinelli, E.; Galli, G.; Paradossi, G. Understanding the Temperature-Responsive Self-Assemblies of Amphiphilic Random Copolymers by SANS in D2O Solution. Macromol. Chem. Phys. 2021. [CrossRef]

49. Sezonenko, T.; Qiu, X.-P.; Winnik, F.M.; Sato, T. Dehydration, Micellization, and Phase Separation of Thermosensitive Polyoxazoline Star Block Copolymers in Aqueous Solution. Macromolecules 2019, 52, 935-944. [CrossRef]

50. Qiu, X.; Koga, T.; Tanaka, F.; Winnik, F.M. New Insights into the Effects of Molecular Weight and End Group on the TemperatureInduced Phase Transition of Poly(N-Isopropylacrylamide) in Water. Sci. China Chem. 2013, 56, 56-64. [CrossRef]

51. Ieong, N.S.; Hasan, M.; Phillips, D.J.; Saaka, Y.; O’Reilly, R.K.; Gibson, M.I. Polymers with Molecular Weight Dependent LCSTs Are Essential for Cooperative Behaviour. Polym. Chem. 2012, 3, 794-799. [CrossRef]

52. Christova, D.; Velichkova, R.; Loos, W.; Goethals, E.J.; Prez, F.D. New Thermo-Responsive Polymer Materials Based on Poly(2Ethyl-2-Oxazoline) Segments. Polymer 2003, 44, 2255-2261. [CrossRef]

53. Yamamoto, S.-I.; Pietrasik, J.; Matyjaszewski, K. The Effect of Structure on the Thermoresponsive Nature of Well-Defined Poly(Oligo(Ethylene Oxide) Methacrylates) Synthesized by ATRP. J. Polym. Sci. Part Polym. Chem. 2008, 46, 194-202. [CrossRef]

54. Prabhu, N.V.; Sharp, K.A. Heat Capacity in Proteins. Annu. Rev. Phys. Chem. 2004, 56, 521-548. [CrossRef] [PubMed]

55. Gómez, J.; Hilser, V.J.; Xie, D.; Freire, E. The Heat Capacity of Proteins. Proteins Struct. Funct. Bioinforma. 1995, 22, 404-412. [CrossRef] [PubMed] 